\title{
Glottic Cancer pN0 TNM Finding v6 and v7
}

National Cancer Institute

\section{Source}

National Cancer Institute. Glottic Cancer pNO TNM Finding v6 and v7. NCI Thesaurus.

Code 64685.

Glottic cancer with no metastasis to regional lymph nodes. (from AJCC 6th and 7th Eds.) 